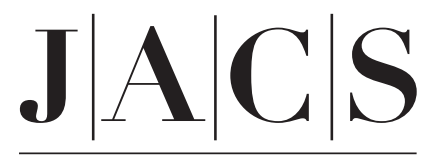

A R T I C L E S

Published on Web 09/01/2004

\title{
Do Electrostatic Interactions with Positively Charged Active Site Groups Tighten the Transition State for Enzymatic Phosphoryl Transfer?
}

\author{
Ivana Nikolic-Hughes, ${ }^{\dagger, \ddagger}$ Douglas C. Rees, ${ }^{\ddagger}, \S$ and Daniel Herschlag ${ }^{\star, \dagger, \| l, \perp}$ \\ Contribution from the Departments of Chemical Engineering, Chemistry, and Biochemistry, \\ Stanford University, Stanford, California 94305, Division of Chemistry and Chemical \\ Engineering and Howard Hughes Medical Institute, California Institute of Technology, \\ Pasadena, California 91125
}

Received April 5, 2004; E-mail: herschla@cmgm.stanford.edu

\begin{abstract}
The effect of electrostatic interactions on the transition-state character for enzymatic phosphoryl transfer has been a subject of much debate. In this work, we investigate the transition state for alkaline phosphatase (AP) using linear free-energy relationships (LFERs). We determined $k_{\text {cat }} / K_{\mathrm{M}}$ for a series of aryl sulfate ester monoanions to obtain the Brønsted coefficient, $\beta_{\mathrm{lg}}$, and compared the value to that obtained previously for a series of aryl phosphorothioate ester dianion substrates. Despite the difference in substrate charge, the observed Brønsted coefficients for AP-catalyzed aryl sulfate and aryl phosphorothioate hydrolysis $(-0.76 \pm 0.14$ and $-0.77 \pm 0.10$, respectively) are strikingly similar, with steric effects being responsible for the uncertainties in these values. Aryl sulfates and aryl phosphates react via similar loose transition states in solution. These observations suggest an apparent equivalency of the transition states for phosphorothioate and sulfate hydrolysis reactions at the AP active site and, thus, negligible effects of active site electrostatic interactions on charge distribution in the transition state.
\end{abstract}

\section{Introduction}

Catalysis is defined as preferential stabilization of a reaction's transition state, relative to its ground state. ${ }^{1}$ Thus, detailed knowledge of the transition-state character for both nonenzymatic and enzymatic reactions is essential to decipher enzymatic catalysis. The least amount of energy is required for an enzyme that stabilizes a transition state closely related to that found in solution, and many enzymatic transition states have indeed been found to be similar to their nonenzymatic counterparts. ${ }^{2}$

Physical organic studies over the past several decades have characterized the nonenzymatic transition state for phosphoryl transfer from phosphate monoesters as loose, with a large amount of bond breaking to the leaving group and only a small amount of bond formation to the nucleophile, presumably resulting in a reduction of negative charge on the nonbridging oxygen atoms of the phosphoryl group, relative to the ground state (eq 1). ${ }^{3}$ As enzymes tend to surround the phosphoryl group with hydrogen bond donors and positively charged groups, it

$\dagger$ Department of Chemical Engineering, Stanford University.

Division of Chemistry and Chemical Engineering, California Institute of Technology.

$\S$ Howard Hughes Medical Institute.

" Department of Biochemistry, Stanford University.

${ }^{\perp}$ Department of Chemistry, Stanford University.

(1) (a) Polanyi, M. Z. Elektrochem. Z. 1921, 27, 142. (b) Pauling, L. Chem. Eng. News 1946, 24, 1375. (c) Jencks, W. P. In Catalysis in Chemistry and Enzymology; McGraw-Hill: New York, 1969.

(2) For example, see: (a) Kempton, J. B.; Withers, S. G. Biochemistry 1992, 34, 9961. (b) Bruner, M.; Horenstein, B. A. Biochemistry 1998, 37, 289. (c) Scheuring, J.; Schramm, V. L. Biochemistry 1997, 36, 4526. (d) Berti, P. J.; Schramm, V. L. J. Am. Chem. Soc. 1997, 119, 12069. See also: (e) Yang, J.; Schenkman, S.; Horenstein, B. A. Biochemistry 2000, 39, 5902. Reviewed in: (f) Schramm, V. L. Curr. Opin. Chem. Biol. 2001, 5, 556.

11814 - J. AM. CHEM. SOC. 2004, 126, 11814-11819 has been proposed numerous times that electrostatic interactions between these positive charges and the phosphoryl group would introduce an energetic incentive to increase the amount of charge on the nonbridging oxygen atoms in the transition state, thereby tightening the transition state, such that there is less bond breaking to the leaving group and more bond formation to the nucleophile (Scheme 1). ${ }^{4}$

Recently, Escherichia coli alkaline phosphatase (AP) has been shown to have activity toward sulfate monoesters in addition to the cognate phosphate monoester substrates. ${ }^{5}$ The AP active site contains two $\mathrm{Zn}^{2+}$ metal ions and an arginine residue that interact directly with the transition state (Scheme 2). ${ }^{6}$ Because

(3) For review, see: (a) Thatcher, G. R. J.; Kluger, R. Adv. Phys. Org. Chem 1989, 25, 99. (b) Hengge, A. C. In Comprehensive Biological Catalysis; Sinnott, M. L., Ed.; Academic Press: London, 1998; Vol. 1, pp 517-542.

(4) For example, see: (a) Breslow, R.; Katz, I. J. Am. Chem. Soc. 1968, 90 7370. (b) Hall, A. D.; Williams, A. Biochemistry 1986, 25, 4784. (c) Mildvan, A. S.; Fry, D. C. Adv. Enzymol. 1987, 59, 241. (d) Reinstein, J.; Schlichting, I.; Wittinghofer, A. Biochemistry 1990, 29, 7451. (e) Bossemeyer, D.; Engh, R. A.; Kinzel, V.; Ponstingl, H.; Huber, R. EMBO J. 1993, 12, 849. (f) Abrahams, J. P.; Leslie, A. G. W.; Lutter, R.; Walker, J. E. Nature 1994, 370, 621. (g) Goldberg, J.; Huang, H.; Kwon, Y.; Greengard, P.; Nairn, A. C.; Kuriyan, J. Nature 1995, 376, 745. (h) Berghuis, A. M.; Lee, E.; Raw, A. S.; Gilman, A. G.; Sprang, S. R. Structure 1996, 4, 1277. (i) Rittinger, K.; Walker, P. A.; Eccleston, J. F.; Smerdon, S. J.; Gamblin, S. J. Nature 1997, 389, 758. (j) Matte, A.; Tari, L. W.; Delbaere, L. T. J. Structure 1998, 6, 413. (k) Schlichting, I.; Reinstein, J. Nat. Struct. Biol. 1999, 6, 721. (1) Singh-Wissmann, K.; Miles, R. D.; Ingram-Smith, C.; Ferry, J. G. Biochemistry 2000, 39, 3671. (m) Madhusudan, A. P.; Xuong, N.-H.; Taylor, S. S. Nat. Struct. Biol. 2002, 9, 273. (n) Delbaere, L. T. J.; Sudom, A. M.; Prasad, L.; Leduc, Y.; Goldie, H. Biochim. Biophys. Acta 2004, 1697, 271. See also: (o) Glennon, T. M.; Warshel, A. Biochemistry 2000, 39, 9641. (p) Hutter, M. C.; Helms, V. Int. J. Quantum Chem. 2003, 95, 479. (q) Cai, M.; Williams, D. C., Jr.; Wang, G.; Lee, B. R.; Peterkofsky, A.; Clore, G. M. J. Biol. Chem. 2003, 278, 25191. (r) Leiros, I.; McSweeney, S.; Hough, E. J. Mol. Biol. 2004, 339, 805.

(5) O'Brien, P. J.; Herschlag, D. J. Am. Chem. Soc. 1998, 120, 12369. 
Scheme 1. Observed and Hypothetical Transition States for Phosphoryl Transfer

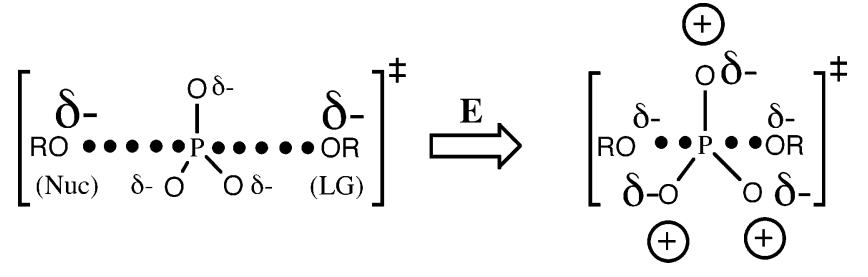

Scheme 2. AP Active Site with a Bound Transition-State Model ${ }^{6}$

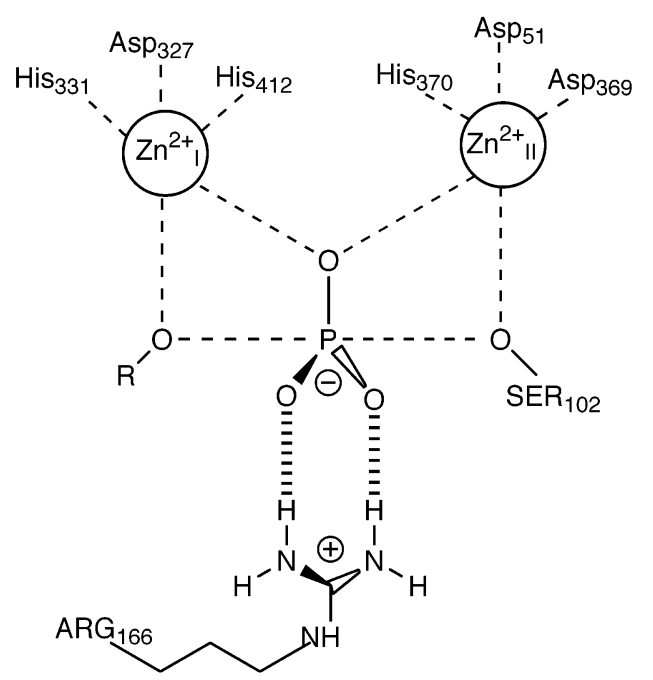

the phosphate monoesters are dianionic, whereas sulfate monoesters are monoanionic (eqs 1 and 2), we considered whether the overall charge difference between these substrates would result in them being "handled" differently within the highly charged AP active site (Scheme 2). Although the $\mathrm{P}-\mathrm{O}$ and $\mathrm{S}-\mathrm{O}$ bonds are very similar in length, ${ }^{7}$ AP catalyzes the phosphate ester reaction with a catalytic proficiency that is at least $10^{10}$ fold greater than the catalytic proficiency for the sulfate ester reaction, corresponding to $13 \mathrm{kcal} / \mathrm{mol}$ of additional transitionstate stabilization for the phosphate compared to the sulfate. ${ }^{5,8}$ Additionally, physical organic studies of nonenzymatic sulfate monoester monoanion hydrolysis suggest a transition state that is loose, akin to that for the phosphate monoester reactions (eqs 1 and 2). ${ }^{9,10}$ These and additional observations (O'Brien, P. J.; Nikolic-Hughes, I.; Herschlag, D, unpublished results) support the notion that charge is of utmost importance to AP catalysis.

Given the proposals for creation of a tighter transition state within the highly charged active site of phosphoryl transfer enzymes, including AP, and the apparent importance of electrostatics in AP catalysis, we were interested in comparing the transition states for AP-catalyzed phosphoryl and sulfuryl transfer. Three classes of models were considered and are depicted in Scheme 3. (1) The strong electrostatic interactions

(6) Holtz, K. M.; Stec, B.; Kantrowitz, E. R. J. Biol. Chem. 1999, 274, 8351.

(7) CRC Handbook of Chemistry and Physics, 75th ed.; Lide, D. R., Ed.; CRC Press: Boca Raton, FL, 1994-1995; pp 9-12.

(8) Lad, C.; Williams, N. H.; Wolfenden, R. Proc. Natl. Acad. Sci. U.S.A 2003, $100,5607$.

(9) See: (a) Kirby, A. J.; Jencks, W. P. J. Am. Chem. Soc. 1965, 87, 3209. (b) Kirby, A. J.; Varvoglis, A. G. J. Am. Chem. Soc. 1967, 89, 415. (c) Benkovic, S. J.; Benkovic, P. A. J. Am. Chem. Soc. 1966, 88, 5504. (d) Hengge, A. C. Acc. Chem. Res. 2002, 35, 105. (e) The nonenzymatic hydrolysis of para-nitrophenyl phosphate and para-nitrophenyl sulfate was found to occur via $\mathrm{P}-\mathrm{O}$ and $\mathrm{S}-\mathrm{O}$ bond cleavage, respectively (ref 9a and c).

(10) Fendler, E. J.; Fendler, J. H. J. Org. Chem. 1968, 33, 3852.
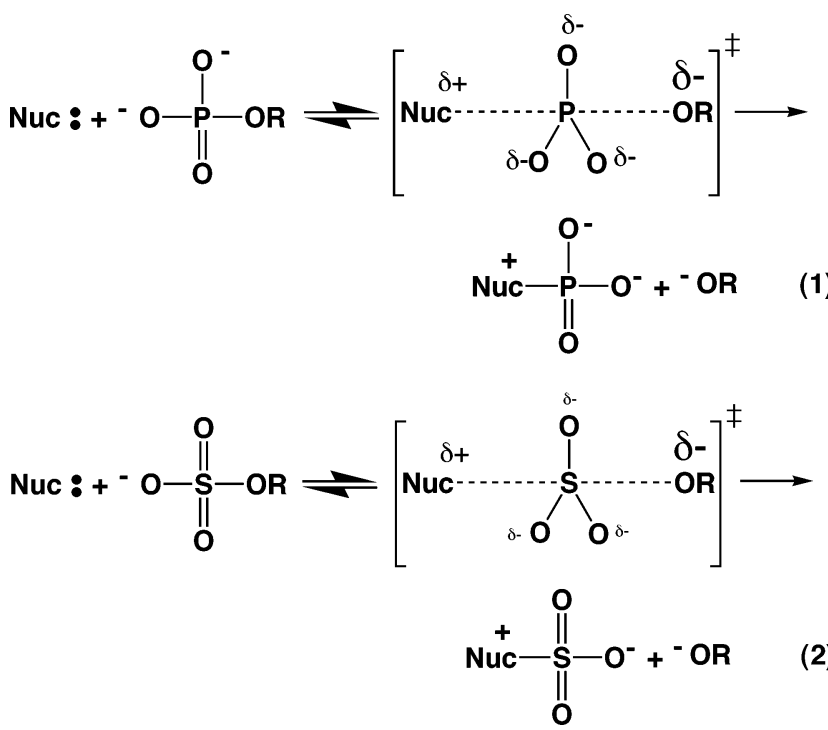

of the AP active site with phosphate monoester dianions result in a tighter transition state, whereas sulfate ester monoanions undergo a smaller change (if any) because their lower charge results in less intimate, more distant electrostatic interactions (Scheme 3A). (2) The lower charge density of the sulfate ester monoanions leads to an imbalance of charge, especially on the nonbridging oxygen that interacts with both active site $\mathrm{Zn}^{2+}$ ions. This charge imbalance creates a large driving force for increasing the charge on this nonbridging oxygen atom in the sulfate ester transition state, whereas the corresponding nonbridging oxygen of the phosphate ester transition state is more highly charged so that there is less of a driving force from interaction with the two $\mathrm{Zn}^{2+}$ ions for a charge increase on this atom. (Scheme 3B depicts an increase in charge for the sulfuryl transfer transition state for all of the nonbridging oxygen atoms relative to the unperturbed transition state (Scheme 3A,C); an increase in charge in the sulfuryl transfer reaction would most simply be accompanied by increasing the bond order to the incoming and outgoing groups, as is also depicted in Scheme 3B.) (3) Bonding in both the phosphoryl and sulfuryl transfer transition states is unchanged relative to solution because the "force" exerted by the active site is insufficient to substantially reorganize the covalent and partially covalent bonds in the transition state (Scheme 3C).

Additionally, there is literature precedent to suggest that if the active site environment indeed affected the transition-state nature, the response of the phosphate ester would be different from that of the sulfate ester. The effect of dimethyl sulfoxide (DMSO) addition on nonenzymatic rate constants has been found to be drastically different for a phosphate ester compared to a sulfate ester ( $10^{6}$ vs 50 -fold rate enhancement in $95 \%$ DMSO, respectively). ${ }^{11}$ This solvent effect presumably arises from a loss of stabilizing ground-state electrostatic interactions between substrate and water when the transition state is reached, as charge is dispersed in the transition state. ${ }^{11 \mathrm{c}}$ Therefore, removing electrostatic interactions (via DMSO addition) is energetically more unfavorable for phosphate than for sulfate

(11) (a) Abell, K. W. Y.; Kirby, A. J. Tetrahedron Lett. 1986, 27, 1085. (b) Hoff, R. H.; Larsen, P.; Hengge, A. C J. Am. Chem. Soc. 2001, 123, 9338. (c) Cheng, H.; Nikolic-Hughes, I.; Wang, J. H.; Deng, H.; O'Brien, P. J. Wu, L.; Zhang, Z.-Y.; Herschlag, D.; Callender, R. J. Am. Chem. Soc. 2002, $124,11295$. 
Scheme 3. Possible Responses of Phosphate and Sulfate Transition States to Electrostatic Interactions within the AP Active Site

\section{A. MODEL 1}
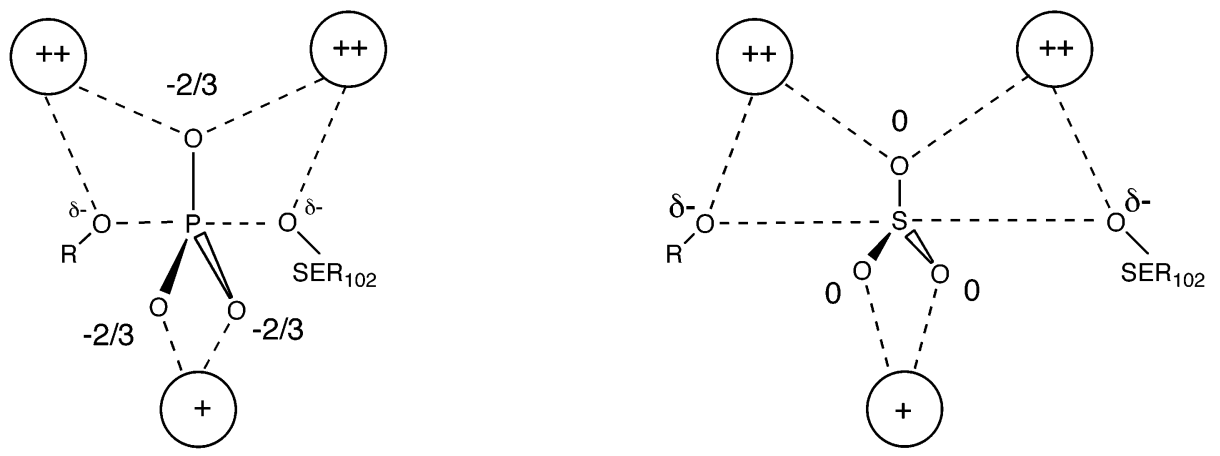

\section{B. MODEL 2}

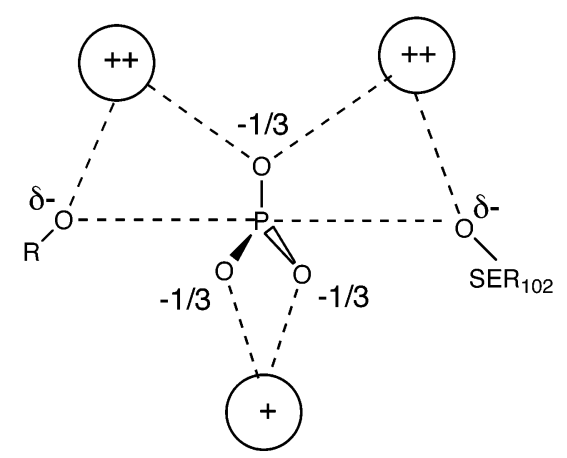

\section{MODEL 3}

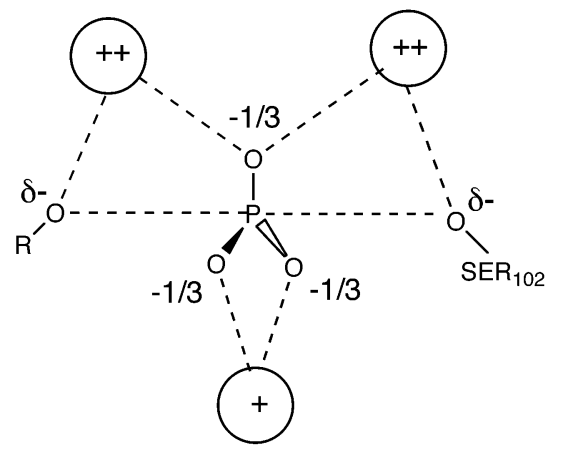

(7.8 $\mathrm{kcal} / \mathrm{mol}$ vs $2.2 \mathrm{kcal} / \mathrm{mol}$, respectively). This suggests that loss of electrostatic interactions with positively charged active site groups in the transition state would be more unfavorable for phosphate than sulfate, and thus a greater force to optimize those interactions, if indeed such a force existed, would be exerted upon a phosphate, as described in model 1 (Scheme 3A).

\section{Results and Discussion}

To determine the effect of electrostatic interactions in the highly charged active site of AP (Scheme 3 and Introduction) we compared linear free-energy relationships (LFERs) for phosphoryl and sulfuryl transfer in solution and in the AP active site. A series of aryl leaving groups was used to determine the LFER coefficient $\beta_{\mathrm{lg}}$, which represents the dependence of the logarithm of the reaction rate constant on the leaving group $\mathrm{p} K_{\mathrm{a}}$. Phosphorothioates were used in the comparison because the APcatalyzed hydrolysis of aryl phosphates is limited by binding
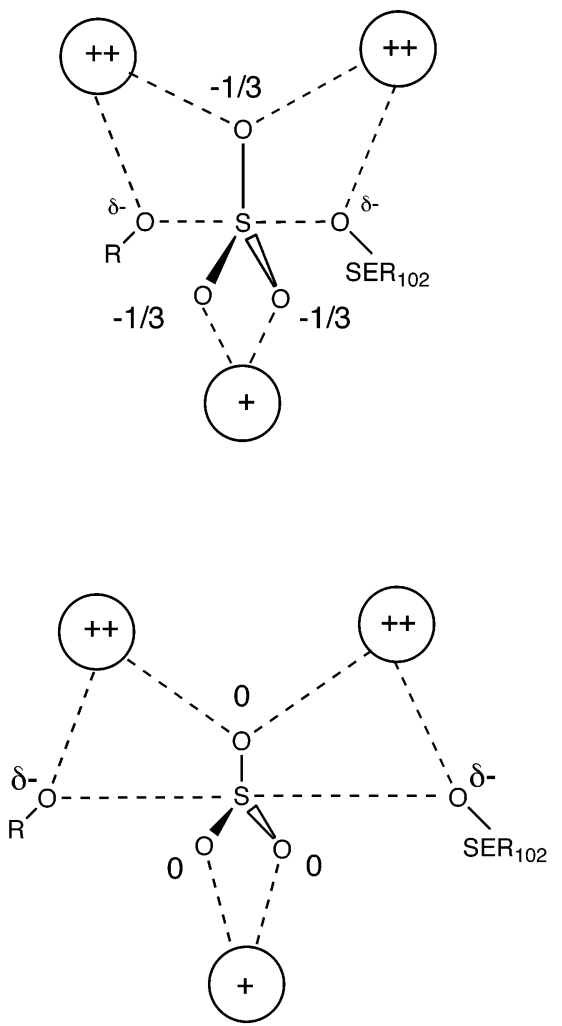

rather than the chemical step, ${ }^{12}$ whereas thio-substitution renders the chemical step rate-limiting. ${ }^{13,14}$

Figure 1 shows a comparison of the leaving group dependence for the aryl sulfate and aryl phosphorothioate nonenzymatic hydrolysis, from literature data and aryl sulfate data obtained in this work (Table 1). ${ }^{10,13}$ These correlations give the same slope, within error, for aryl sulfates and aryl phosphorothioates, with $\beta_{\lg }$ values of -1.2 . The results are consistent with the previous conclusions that these reactions proceed through similar, loose transition states in aqueous solution. ${ }^{9}$

We next determined a Brønsted correlation for AP-catalyzed hydrolysis of aryl sulfates, using a broader series of synthesized aryl sulfate esters, and compared this LFER to that previously

(12) (a) Simopoulos, T. T.; Jencks, W. P. Biochemistry 1994, 33, 10375. (b) Hengge, A. C.; Edens, W. A.; Elsing, H. J. Am. Chem. Soc. 1994, 116, 5045 .

(13) Hollfelder, F.; Herschlag, D. Biochemistry 1995, 34, 12255.

(14) Holtz, K. M.; Catrina, I. E.; Hengge, A. C.; Kantrowitz, E. R. Biochemistry 2000, 39, 9451 


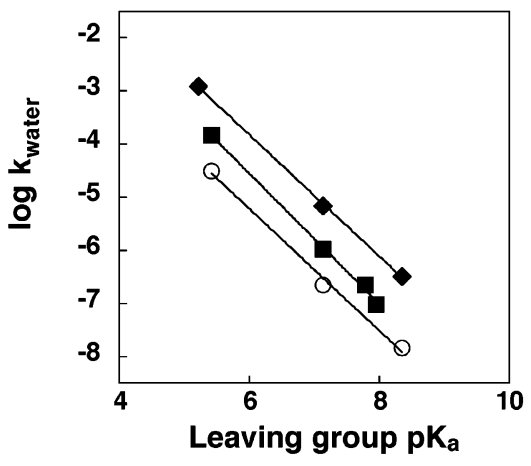

Figure 1. Leaving group dependence for nonenzymatic hydrolysis of aryl sulfates $(\boldsymbol{\square}, \mathbf{)}$ ) and aryl phosphorothioates $(\bigcirc)$. In the current work, aryl sulfate esters were synthesized as described previously, ${ }^{10}$ and their reactions (ש) were conducted at $90{ }^{\circ} \mathrm{C}$, as described in the Methods section. Aryl sulfate hydrolysis data by Fendler and Fendler $(\bullet)^{10}$ were obtained at 100 ${ }^{\circ} \mathrm{C}$, and aryl phosphorothioate data by Hollfelder and Herschlag $(O)^{13}$ were obtained at $37^{\circ} \mathrm{C}$. The phenol leaving groups and their $\mathrm{p} K_{\mathrm{a}}$ values for the (ם) series are: 3,4-dinitro (5.42), 4-nitro (7.14), 4-chloro, 3-nitro (7.78), and 4-cyano (7.95); for the $(\checkmark)$ series: 2,5-dinitro (5.22), 4-nitro (7.14), and 3-nitro (8.35); for the $(O)$ series: 3,4-dinitro (5.42), 4-nitro (7.14), and 3 -nitro (8.35). The solid lines represent the least-squares fit to the individual data series with slopes $\left(\beta_{\mathrm{lg}}\right)$ of $-1.23 \pm 0.04(\boldsymbol{\square}),-1.15 \pm 0.01(\diamond)$, and $-1.15 \pm 0.07(O)$. All fits gave $R^{2}>0.99$.

Table 1. Rate Constants for Nonenzymatic ArylSulfate Hydrolysis at $90^{\circ} \mathrm{C}, \mathrm{pH} 10$ (see Methods section)

\begin{tabular}{lccc}
\hline \multicolumn{1}{c}{ aryl substituent } & phenol $\mathrm{pK}_{\mathrm{a}}$ & [substrate] $(\mathrm{mM})$ & $k_{\text {water }}\left(\mathrm{s}^{-1}\right)$ \\
\hline 3,4-dinitro & 5.42 & $5-50$ & $1.4 \times 10^{-4}$ \\
4-nitro & 7.14 & $1-10$ & $1.0 \times 10^{-6}$ \\
4-chloro, 3-nitro & 7.78 & $12.5-100$ & $1.9 \times 10^{-7}$ \\
4-cyano & 7.95 & $2.5-25$ & $1.0 \times 10^{-7}$ \\
\hline
\end{tabular}

Table 2. Rate Constants for AP-Catalyzed Aryl Sulfate Hydrolysis at $60^{\circ} \mathrm{C}, \mathrm{pH} 10$ (see Methods section)

\begin{tabular}{lccc}
\hline \multicolumn{1}{c}{ aryl substituent } & phenol $K_{\mathrm{a}}$ & [substrate] $(\mathrm{mM})$ & $k_{\text {caa }} / K_{\mathrm{M}}\left(\mathrm{M}^{-1} \mathrm{~s}^{-1}\right)$ \\
\hline 4-nitro & 7.14 & $0.5-40$ & $1.4 \times 10^{-2}$ \\
4-chloro, 3-nitro & 7.78 & $2.5-20$ & $6.3 \times 10^{-2}$ \\
4-cyano & 7.95 & $5-40$ & $7.6 \times 10^{-3}$ \\
3-nitro & 8.35 & $10-55$ & $2.4 \times 10^{-2}$ \\
3,4-dichloro & 8.55 & $10-110$ & $5.4 \times 10^{-3}$ \\
3-chloro & 9.02 & $8-90$ & $1.1 \times 10^{-2}$ \\
3-bromo & 9.11 & $8-45$ & $3.2 \times 10^{-2}$ \\
3-fluoro & 9.29 & $10-110$ & $4.1 \times 10^{-3}$ \\
4-bromo & 9.37 & $10-110$ & $4.9 \times 10^{-3}$ \\
4-chloro & 9.38 & $8-90$ & $3.8 \times 10^{-3}$ \\
4-fluoro & 9.95 & $10-110$ & $1.1 \times 10^{-3}$ \\
parent & 9.95 & $12.5-90$ & $2.0 \times 10^{-3}$ \\
4-methoxy & 10.21 & $10-110$ & $4.9 \times 10^{-4}$ \\
& & & \\
\hline
\end{tabular}

obtained for aryl phosphorothioates (Table 2 and Figure 2). ${ }^{13}$ As noted in the Introduction, AP is much more efficient at catalyzing the cognate phosphoryl transfer reaction. Nevertheless, similar values of $\beta_{\lg }$ of $-0.76 \pm 0.14$ and $-0.77 \pm 0.10$ were obtained for the sulfate and phosphorothioate esters, respectively (Figure 2). Much of the scatter present in the individual LFERs in Figure 2 is eliminated by plotting the logarithm of the rate constant for each aryl sulfate as a function of the logarithm of the rate constant for the aryl phosphorothioate with the same leaving group (Figure 3). A single line with a slope of $1.00 \pm 0.08$ gives a good fit to the data, suggesting that idiosyncratic binding effects from the aryl substituents are the main source of scatter and deviations in the enzymatic LFER plots of Figure 2, as was previously proposed. ${ }^{13,15}$ This strong correlation indicates that the $\beta_{\lg }$ values for AP-catalyzed phosphate and sulfate hydrolysis are virtually identical and thus

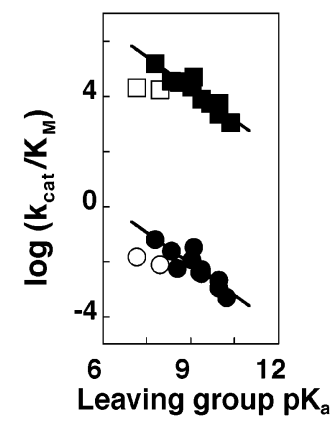

Figure 2. AP-catalyzed hydrolysis of aryl phosphorothioates $(\square)^{13}$ and aryl sulfates $(\bullet)$. Aryl sulfates were synthesized, ${ }^{10}$ and AP was purified as described previously. ${ }^{5}$ Aryl sulfate AP-catalyzed hydrolysis reactions were performed in $0.1 \mathrm{M}$ CHES, $\mathrm{pH} 10.0,0.5 \mathrm{M} \mathrm{NaCl}$ at $60^{\circ} \mathrm{C}$ (see Methods section). The sulfate series phenol leaving groups and their $\mathrm{p} K_{\mathrm{a}}$ values are as follows: 4-nitro (7.14), 4-chloro, 3-nitro (7.78), 4-cyano (7.95), 3-nitro (8.35), 3,4-dichloro (8.55), 3-chloro (9.02), 3-bromo (9.11), 3-fluoro (9.29), 4-bromo (9.37), 4-chloro (9.38), 4-fluoro (9.95), parent (9.95), and 4-methoxy (10.21). The solid lines represent the best least-squares fit to the data, with a slope $\left(\beta_{\mathrm{lg}}\right)$ of $-0.76 \pm 0.14$ for sulfates and $-0.77 \pm 0.10$ for phosphorothioates. Rate constants for 4-nitrophenyl and 4-cyanophenyl substituents are represented by open symbols in both series and were not included in the linear fits. ${ }^{13}$

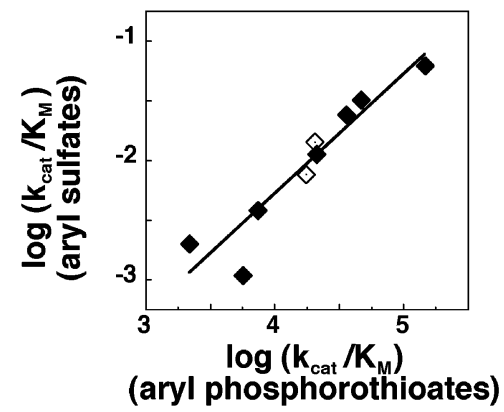

Figure 3. Rate constant for AP-catalyzed hydrolysis of aryl sulfates as a function of the rate constant for aryl phosphorothioates with the same leaving group. Data taken from Figure 2. The solid line represents the best leastsquares fit to the data, with a slope of $1.00 \pm 0.08$. The open symbols represent the points for 4-nitrophenyl and 4-cyanophenyl substituents and are included in the fit. ${ }^{13}$

suggests that the transition states for these enzymatic reactions are similar. ${ }^{16}$

The apparent likeness of the transition states for phosphate and sulfate AP-catalyzed hydrolysis is most simply accounted for by model 3 above (Scheme 3C), according to which the electrostatic interactions in the AP active site have a negligible effect on charge distribution of the axial bonds in the transition state for AP-catalyzed reactions. Furthermore, our data cannot be accounted for by either model 1 or model 2 (Scheme 3A,B). However, we cannot rule out a coincidental scenario in which models 1 and 2 hold simultaneously, with forces exerted on both phosphate and sulfate esters to tighten their transition states to precisely the same extent. The observed values of $\beta_{\lg }$ are consistent with those expected based on the solution hydrolysis values of -1.2 after correction for the stronger nucleophile

(15) (a) O'Brien, P. J.; Herschlag, D. J. Am. Chem. Soc. 1999, 121, 11022. (b) O'Brien, P. J.; Herschlag, D. Biochemistry 2002, 41, 3207.

(16) The looseness or tightness of a transition state is determined by the bonding to both the departing and incoming groups. Herein we have measured $\beta_{\mathrm{lg}}$ and not $\beta_{\text {nuc }}$, so that we have an experimental measure of bond cleavage but not bond formation. However, the AP-catalyzed reactions are highly symmetrical (Scheme 2), having an oxyanionic nucleophile and leaving group of similar $\mathrm{p} K_{\mathrm{a}}$ 's; LFERs for nonenzymatic reactions suggest that differences in the $\mathrm{p} K_{\mathrm{a}}$ values of this order for the incoming and leaving groups do not lead to large transition-state asymmetries (refs 17 and 18). 
A. Charge donation from the non-bridging oxygens in a loose transition state

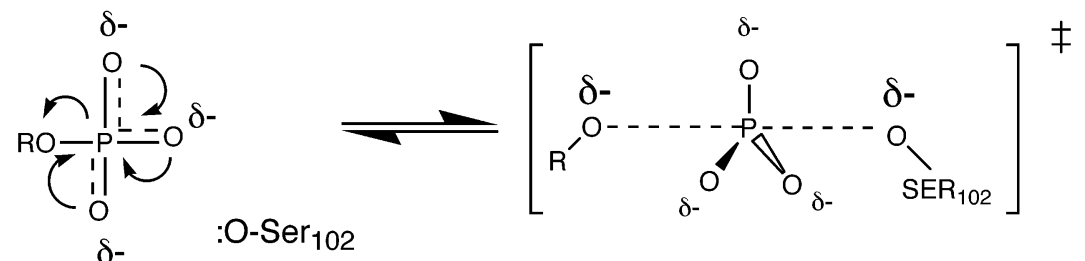

B. No charge donation from the non-bridging oxygens in a loose transition state

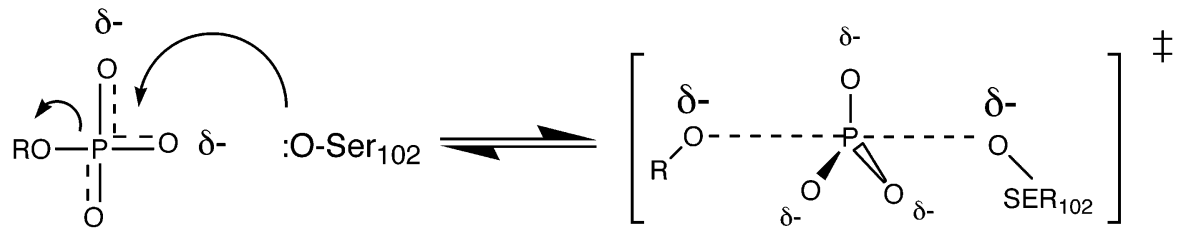

\section{Possible resonance forms for metaphosphate}<smiles>O=P(O)(O[Na])O[AlH2]</smiles>

vs.

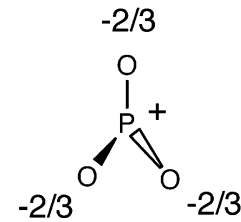

present and binding interactions of both bridging and nonbridging oxygens with the active site $\mathrm{Zn}^{2+}$ ions, as described previously. ${ }^{15 b}$ On the basis of the above observations and considerations, we conclude that model 3 is most likely.

There are several possible explanations for the absence of an effect of electrostatic interactions on transition-state nature. These are described below.

The classical view of reactions proceeding via loose, metaphosphate-like transition states is that charge donation from the nonbridging oxygen atoms helps expel the leaving group (Scheme 4A). From this standpoint, electrostatic interactions with the nonbridging oxygen atoms would inhibit this charge donation. However, the charge distribution is not known, and computational work has suggested that metaphosphate may be better described by a resonance form with one or two positive charges on the phosphorus atom so that charge donation from the nonbridging phosphoryl oxygen atoms may not occur in the transition state (Scheme $4 \mathrm{~B}, \mathrm{C}$ ). ${ }^{3 \mathrm{~b}, 19}$ It is also possible that the negative charge is not evenly distributed among the nonbridging phosphoryl oxygen atoms, but rather rearranges to accommodate differential positive potentials within active sites. ${ }^{20}$

Although addition of covalent bonds to the phosphoryl oxygen atoms to give phosphate di- and triesters tightens the transition state, ionic interactions with metal ions or side chains are expected to be weaker and give less of a perturbation to the

(17) (a) Herschlag, D.; Jencks, W. P. J. Am. Chem. Soc. 1987, 109, 4665. (b) Herschlag, D.; Jencks, W. P. Biochemistry 1990, 29, 5172. (c) Admiraal, S. J.; Herschlag, D. Chem. Biol. 1995, 2, 729.

(18) Skoog, M. T.; Jencks, W. P. J. Am. Chem. Soc. 1984, 106, 7597

(19) (a) Rajca, A.; Rice, J.; Streitweiser, A.; Schaefer, H. J. Am. Chem. Soc. 1987, 109, 4189. (b) Horn, H.; Alhrichs, R. J. Am. Chem. Soc. 1990, 112 2121

(20) (a) Spiro, T. G. In Inorganic Biochemistry; Eichhorn, G. L., Ed.; Elsevier: Amsterdam, 1973; Vol. 1, pp 549-581. (b) Baraniak, J.; Frey, P. A. J. Am. Chem. Soc. 1988, 110, 4059.
VS.<smiles></smiles>

covalent electronic structure of the transition state. This viewpoint is supported by previous observations in model systems. $\mathrm{Mg}^{2+}$ or $\mathrm{Ca}^{2+}$ bound to phosphoanhydrides such as ATP, phosphate monoesters, or phosphorylated pyridines in aqueous reactions does not tighten the transition state. ${ }^{17}$ Similarly, the transition states for hydrolysis of phosphates by E. coli alkaline phosphatase (AP) and Yersinia protein tyrosine phosphatase are unchanged upon removal of positively charged active site arginine residues, as judged by LFERs and isotope effects, respectively. ${ }^{14,15 a, 21}$ These observations suggest that electrostatic interactions with positively charged groups do not have large effects on the nature of transition state for phosphoryl transfer, consistent with model 3 and the results herein (Scheme 3C). This conclusion is also consistent with previous substituent effect studies in model systems that implied that the transition state is rather difficult to change because the energy surface near the transition state is steep. ${ }^{17}$

It is also possible that other electrostatic interactions limit charge flow to the nonbridging oxygen atoms (Scheme 5; dots depict the strength of electrotatic interactions). As noted above, the interaction of the nonbridging oxygen atoms with the $\mathrm{Zn}^{2+}$ ions and positively charged Arg side chain (Scheme 2) presumably provides a driving force for accumulation of additional charge on these oxygen atoms. However, as the incoming and outgoing oxygen atoms also interact with the active site $\mathrm{Zn}^{2+}$ ions (Scheme 2), ${ }^{6}$ loss of charge on these atoms would weaken their electrostatic interactions. Thus, a balance of interactions, along with any barrier for electron rearrangement from the otherwise most stable transition state (see Introduction), may render formation of the unperturbed transition state most

(21) Hoff, R. H.; Wu, L.; Zhou, B.; Zhang, Z.; Hengge, A. C. J. Am. Chem. Soc. 1999, 121, 9514 
Scheme 5. Possible Balance of Electrostatic Interactions in the AP Active Site

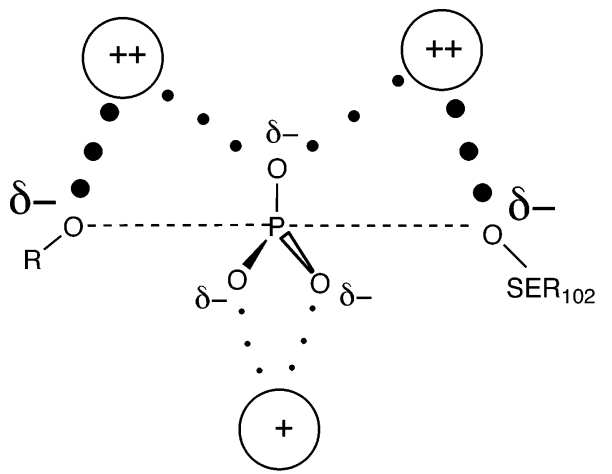

favorable in the AP active site. Also, the absence of a change in transition-state structure upon removal of the active site Arg residue, as determined by $\beta_{\mathrm{lg}}$, provides no indication of an electronic rearrangement of the transition state induced by $\operatorname{Arg} ;{ }^{14,15 a}$ as Arg only interacts with the nonbridging oxygen atoms, its effect would not be subject to the balance of interactions.

In conclusion, it appears that the interactions in the AP active site stabilize the transition state found in the solution reaction, so that AP uses the minimal amount of energy to achieve considerable rate enhancements. ${ }^{5,8,15 b}$ The challenge we now face is to understand how these active site interactions cause the observed stabilization of more than $25 \mathrm{kcal} / \mathrm{mol}$ for the phosphoryl transfer reaction, and what active site features are responsible for the enormous discrimination exhibited against the sulfate ester transition state..$^{5,8,15 b}$

\section{Methods}

Nonenzymatic Sulfate Ester Hydrolysis Reactions. Standard reaction conditions were $0.1 \mathrm{M} \mathrm{NaCHES}, \mathrm{pH} 10.0,0.5 \mathrm{M} \mathrm{NaCl}$, and $90{ }^{\circ} \mathrm{C}$. The reaction was followed in the $\mathrm{pH}$-independent region, to ensure that $\mathrm{S}-\mathrm{O}$ bond cleavage was monitored (see ref $9 \mathrm{c}$ ). The appearance of the phenolate product was monitored noncontinuously using a Uvikon XL spectrophotometer at the following wavelengths: 3,4-dinitro (403 nm), 4-nitro (410 nm), 4-chloro, 3-nitro (403 nm), and 4-cyano $(300 \mathrm{~nm})$. Rate constants, $k_{\text {water, }}$, were determined from initial rates ( $\leq 2 \%$ reaction), and the reactions were shown to be first-order in substrate by varying concentration $8-10$-fold (Table 1 ). vs.

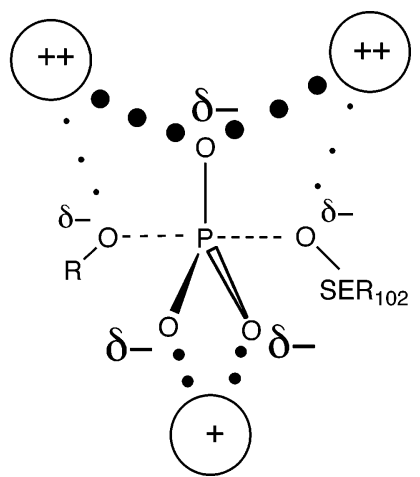

Enzymatic Sulfate Ester Hydrolysis Reactions. Standard reaction conditions were $0.1 \mathrm{M} \mathrm{NaCHES}, \mathrm{pH} 10.0,0.5 \mathrm{M} \mathrm{NaCl}, 10 \mathrm{mM}$ $\mathrm{MgCl}_{2}$, and $1 \mathrm{mM} \mathrm{ZnSO}_{4}$ at $60{ }^{\circ} \mathrm{C}$. The appearance of the phenolate product was monitored noncontinuously using a Uvikon XL spectrophotometer at the following wavelengths: 4-nitro $(410 \mathrm{~nm}), 4$-chloro, 3-nitro $(403 \mathrm{~nm})$, 4-cyano $(300 \mathrm{~nm}), 3$-nitro $(400 \mathrm{~nm}), 3,4$-dichloro (314 nm), 3-chloro (292 nm), 3-bromo (293 nm), 3-fluoro (283 nm), 4-bromo (292 nm), 4-chloro (298 nm), 4-fluoro (293 nm), parent (292 $\mathrm{nm})$, and 4-methoxy $(300 \mathrm{~nm})$. For hydrolysis of 3,4-dichloro-, 3-chloro-, 3-fluoro-, 4-bromo-, and 4-chloro-phenyl sulfate, aliquots were taken from reactions and diluted 10 -fold for absorbance readings, whereas for all the other reactions absorbance measurements were obtained without dilution. Rate constants were obtained from initial rates ( $\leq 5 \%$ reaction). Product formation was linear in all cases, and AP was shown to retain $>80 \%$ of the activity during the course of the slowest reactions $(\sim 1$ week). Reactions were shown to be first-order in substrate and enzyme by varying substrate concentration over a range of 6-80-fold (Table 2) and enzyme concentration from 1 to $5 \mu \mathrm{M}$. The apparent second-order rate constants, $k_{\text {cat }} / K_{\mathrm{M}}$, obtained are reported per active site in Table 2 .

Acknowledgment. We are grateful to P. Dervan for generously sharing laboratory space and equipment for the aryl sulfate syntheses, A. Heckel and P. Arora for synthetic advice, J. Zalatan for helpful discussions, P. O'Brien and members of the Herschlag and Rees labs for comments on the manuscript. This work was funded by grants from the NIH to D.H. (GM64798) and D.C.R. (GM45162). I.N-H. is an AHA Predoctoral Fellow.

JA0480421 